\title{
Assessing Multicultural Competence of Counsellors in Public Universities in Ghana
}

\author{
Ebenezer Kobina Mensah
}

MPhil Graduate, Department of Guidance and Counselling, University of Cape Coast, Cape Coast, Ghana. Email:ek.mensah@yahoo.com Tel: +233543169914

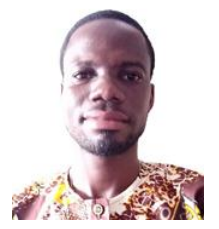

\begin{abstract}
A person's cognition defines the cultural mindset, religious beliefs and way of life. Culture affords its adherents with a theoretical basis for the understanding of sickness and emotive misery. This study, therefore, aimed at assessing multicultural competence of counsellors in the public universities in Ghana. The study adopted the descriptive survey design and mainly questionnaire (Multicultural Competence Questionnaire, [MCQ]) to obtain data. A sample of 45 counsellors was used for the study comprising 25 male counsellors and 20 female counsellors. The study used descriptive statistical tools (means and standard deviations) to analyse data obtained. The study revealed that counsellors sampled perceived their cultural competency to be low as measured on all sections (Knowledge, Skills and Awareness). This low cultural competence is portrayed by looking at the overall means on the sections as well as the overall mean (2.34) of the MCQ whose mean scores obtained were lower than the standard benchmark (2.50). From the results obtained, it is recommended among others that counsellors should capitalise on the low multicultural counselling competence to attend multicultural awareness training programme about Ghanaian cultural beliefs and ethnic diversity to increase their competence. Also, multicultural counselling should be infused in counselling programmes and training in Ghana.
\end{abstract}

Keywords: Assessing, Skills, Awareness, Knowledge, Culture, Multicultural competence, Ghanaian public universities.

Citation | Ebenezer Kobina Mensah (2019). Assessing Multicultural Competence of Counsellors in Public Universities in Ghana. Journal of Education and e-Learning Research, 6(3): 142148 . History:

History:

Received: 29 March 2019

Revised: 6 May 2019

Accepted: 10 June 2019

Published: 28 August 2019

Licensed: This work is licensed under a Creative Commons

Attribution 3.0 License $($ (c) E E

Publisher: Asian Online Journal Publishing Group
Funding: This study received no specific financial support.

Competing Interests: The author declares that there are no conflicts of interests regarding the publication of this paper.

Transparency: The author confirms that the manuscript is an honest, Transparency: The author confirms that the manuscript is an honest,
accurate, and transparent account of the study was reported; that no vital accurate, and transparent account of the study was reported; that no vital
features of the study have been omitted; and that any discrepancies from the features of the study have been omitte
study as planned have been explained.

Ethical: This study follows all ethical practices during writing.

\section{Contents}

1. Introduction

2. Methods

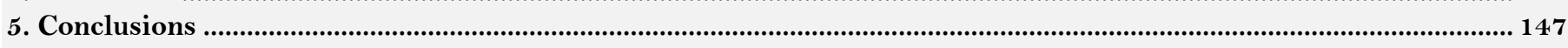

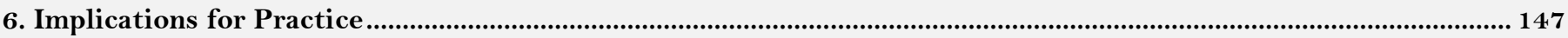

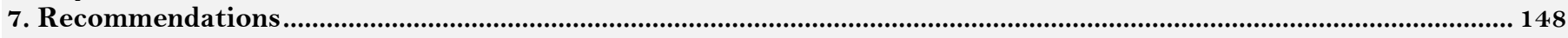

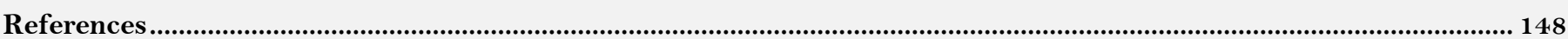




\section{Contribution of this paper to the literature}

This study contributes to the existing literature by evolving the understanding of Ghanaians on multicultural competence thereby highlighting the need for diversity and inclusion of the multiethnic Ghanaian cultural values into the services and training of student service professionals such as counsellors, academic advisors, etc.

\section{Introduction}

A person's cognition defines the cultural mindset, religious beliefs and way of life. Culture affords its adherents with a theoretical basis for the understanding of sickness and emotive misery. This proposes methods of therapeutic interventions which bode well in that cultural context. The theoretical conventions underlying the practice of counselling depend on models of human disposition, passionate troubling and therapeutic interventions which stem legitimately from the understood cultural conventions around the 'self' based on Euro-American cultures (Talib, 2010). This self is seen as an individualist, which makes the practice of counselling difficult in Ghana. The practice of counselling will be effective when these assumptions are adapted and merged with the Ghanaian culture which views the self as collectivist.

A lot has been discussed about the influence of cultural variables on the counselling practice. In terms of psychological organisations, counsellors through the Association for Non-White Concerns in Personnel and Guidance and Multicultural counselling Development were the first to expansively discuss and examine issues of culture (Sue et al., 1982). The American Psychological Association (APA) likewise' contribution to the development of the field of multicultural counselling practices is worthy to be noted (Sue et al., 2009). The APA developed and adopted a Guideline on Multicultural Education, Training, Research, Practice, and Organisational Change for psychologists. This impacted the counselling services, instruction, teaching and inquiry (APA as cited in Sue et al. (2009)). The framework for counselling practices is provided in the guidelines; counsellors are invigorated to relate culturally apt skills in their practices. Counselling practitioners must develop abilities and procedures that are tailored towards the distinctive beliefs and sociocultural experiences of clients. Ghanaian counsellors, therefore, need to integrate the understanding of a client's cultural foundation into the counselling process.

As cited earlier in this section, multicultural counselling competency can be viewed as the grouping of a counsellors' skills, attitudes-beliefs and knowledge concerning the understandings of smaller ethnic and tribal groups' differences in culture (Sue and Sue, 2003). Sue and Sue (2016) itemised six features in cultural terms a knowledgeable counsellor should possess. Specifically, culturally competent counsellors include awareness in six dimensions: (1) consciousness of social and political dynamics which have an impact on help-seekers; (2) attentiveness to variances in values, societal classes and linguistic can be an obstacle to the counselling process; (3) being mindful of the influence of background experiences; (4) consciousness of know-how, credibility and absence of resemblances can sway help-seekers' receptiveness of the counselling process; (5) consciousness of the understanding and expertise that are desirable for suitable discourse which involves diverse styles to match dissimilar ethnic orientations; and (6) consciousness of counsellors' preconceived notion. Multicultural knowledge comprises a critical ingredient in multicultural competence (Sodowsky et al., 1998).

Because all behaviours are scholarly and exhibited in a specific sociocultural framework, the culturally knowledgeable counsellor needs to attend to a client's difficulty in a culturally contextual setting. Multiculturalism outlines established approaches and behaviours suggestive of the capability to create, preserve and effectively complete a therapeutic connection with clients from different cultural experiences (Lee, 2013). In going through the literature on multicultural competence, culturally-experienced counsellors are labelled as skilful across three domains: knowledge, skills and self-awareness (attitude-belief). These three domains are presented as follows.

(1) The Knowledge: Multiculturalism encompasses having the understanding of how age, social class, gender, tribe, traditions, cultural origin, religion, sexuality, ill health, linguistic and socioeconomic prestige may have an impact on the lives of help-seekers and help-seeking practise. Counsellors with multicultural knowledge are aware of the degree of cultural and past events with regards to backgrounds of psychological philosophies and practices, as well as the impacts of such problems as coercion, preconception, discrimination, insufficiency, labelling, stigmatisation, and marginalisation (Sue and Sue, 2003).

(2) The Awareness (Attitude-Beliefs): A counsellors' cultural competency originates by mindfulness of a person's identifiable belief (culture) in an association with new cultures, and a cognisance of the culturallyrelated expectations, whether with or without permission governs a life, with or without permission. The primarily comprehensive subject is one of intrapersonal attentiveness. This is achieved over a logical consideration of a person's identifiable philosophies, attitudes and approaches and is mostly completed over self-examination, self-monitoring, and thoughtful self-assessment. Sue (2008) revealed that if help-seeking professionals were conscious of the effects of culture on their disposition and social lifestyles, then counsellors could well be able to recognise the approaches which cultural values and traditions impact the behaviours of the client, relations, beliefs and lifetime aims.

(3) The Skills: Ivey's (as cited in Ivey (1994)) classification of personal efficacy sets the phase for professionals in the area of counselling to develop their skills by describing culturally-competent professionals as active conversationalists in a cultural-context. The classical icon provides a structure for relating the knowledge of culture in the counselling discourses and therapeutic strategies. Sue and Sue (2016) indicated that the culturally-skilled counselling professionals are in the active process of increasing and practising applicable, significant and thoughtful mediation approaches and expertise in helping clients of diverse cultures.

Multicultural counselling competence ideology is a central field to guarantee counsellors to exhibit competence in a culture of sensitivity, whole-hearted, positive, confidence as well as well-informed practices. Multicultural competence measurement is a multidimensional development involving the assessment of a counsellor proficiencies within a particular ethnic group (Hays, 2008). This assessment ensures the mindfulness of control problems among tribes in a reaction to a fight against social injustice, beliefs, attitudes, values, sexual orientation, religion and ethnic diversity. It appears that counsellors in Ghanaian public universities attempt to comprehend the diverse nature of 
clients in these public universities, including differences interrelated towards attitude, customs, norms, age group, tribe, cultural values, beliefs, gender, spirituality, religion, sex, gender issues and socio-economic status. To achieve this, counsellors in Ghana need to be assessed on the scope of multicultural competencies: skill, attitude-beliefs and knowledge domains Sue and Sue (2016).

The studies conducted by Arthur and Achenbach (2002) and Dorazio (2013) reported cultural variables such as beliefs, norms, customs etc., may dare counsellors and clients in relation to their sincerity during counselling sessions and the counsellors must be familiar with cultural factors influencing one's openness to counselling. However, it is not known what the situation is in Ghanaian public universities. It is against this background that this study sought to assess counsellors in Ghanaian public universities' multicultural competences. This is in line with the assertion made by Hays (2008) testified that the evaluation and assessment of counsellors' competence are essential to safeguard culturally suitable services of counselling to a progressively different client. This study, therefore, aimed at assessing multicultural competence of counsellors in the public universities in Ghana. The following research question guided the study:

(1) How do Ghanaian counsellors rate their multicultural competence on the dimension of knowledge, skills and attitude-beliefs (self-awareness), knowledge and skills in public universities in Ghana?

\section{Methods \\ 2.1. Research Design}

The descriptive survey was used in this study. The aim was to produce a 'snapshot' of awareness of attitudebeliefs (awareness), understanding (knowledge) and abilities (skills) that counsellors need to function effectively with diverse people (Sue, 2001; Ridley and Kleiner, 2003). Similarly, Fraenkel and Wallen (2000) indicated that cross-sectional survey has the potential of providing a lot of useful information about the subjects of the study, for instance, how they perceived their multicultural knowledge competency.

\subsection{Population}

The target population of this study was all counsellors and teachers of counselling programmes in all the public universities in Ghana. Out of the public universities in Ghana, four of them served as the accessible population for the study. Conversely, the estimated accessible population was 45 .

\subsection{Sampling Procedure}

In this study, stratified and census sampling techniques were used. The first stage (stratified sampling technique) involved categorisation of universities into two groups, namely; public and private universities. Furthermore, the public university was subdivided into counsellor trainee and non-counsellor trainee universities. The second stage used the census sampling technique to selected participants from the accessible population (Molenberghs, 2013). In all, 45 counsellors formed the sample for the study.

\subsection{Data Collection Instrument}

The study used a questionnaire to collect data. The researcher developed a Multicultural Competence Questionnaire (MCQ). There were three sections on the questionnaire, Section A was labelled Knowledge with nine items; Section B was labelled Skills with eight items, and Section C was labelled Awareness with 13 items. The questionnaire was content-validated by two experts in the field of counselling and Ghanaian cultural values in the Department of Guidance and counselling and Department of History at the University of Cape Coast in Ghana. I pilot-tested the MCQ instrument at the University of Professional Studies and University of Mines and Technology in the Greater Accra and Western Regions of Ghana respectively, with similar characteristics as those that were used for the actual study in the selected four public universities. Ten participants were selected for the pilot-test. In all, there were 6 males and 4 females who took part in the pilot- test with each participant responding to the instrument. The reliability estimates obtained ranged from 0.88 to 0.91 on the MCQ with an overall reliability estimate of 0.88 .

\subsection{Data Collection Procedures}

Prior to the actual data collection, the four public universities were visited by the investigator to create rapport between the researcher and the universities in question and also agree on when to collect the data. For every respondent, I gave the questionnaire to, I enlightened the aims of the research as well as assuring them of confidentiality of their responses.

\subsection{Data Analysis}

Data obtained were analysed by sections on the questionnaire. Descriptive statistical tools, namely, means and standard deviations were used to answer the research question. The means of individual items of the section and section means were ranked against a standard benchmark (decision rule) I have computed to determine which items deserve consideration. For example, all sections had the scoring keys of 1, 2, 3 and 4, making 4 items. The standard benchmark was computed as $\frac{1+2+3+4}{4}=2.5$. The criterion for judging the competence of counsellors was that a higher mean above the standard benchmark shows that the majority of the participants indicated that they have high multicultural competence while a mean below the standard benchmark indicates low multicultural counselling competence.

\section{Results}

A sample of 45 counsellors from four public universities in Ghana was involved in the study. The demographic characteristics of the participants include their gender, a total of multiculturalism programmes engaged and multicultural workshop grace with their presence. These elements were explored in order to offer a foundation for distinguishing amongst answers, subsequently; totalled answers might ignore some relevant quarantined issues. 
The majority $(43,95.6 \%)$ of the participants have not completed any multicultural training course, while $2(4.4 \%)$ have completed 1-2 multicultural training courses. Again, it was shown that the majority of the participants, $95.6 \%$ have not received any specialised training through workshops. The rest of the participants (2) have received more than 3 specialised training in multicultural counselling through a workshop. The Research Question that guided the study sought to determine counsellor's multicultural competence. Three sections were developed to assess participants.

\subsection{Knowledge Section}

The first section explores the participants' knowledge and understanding of the Ghanaian culture with regards to the practices of counselling services. The results are captured in Table 1.

Table-1. Knowledge competency.

\begin{tabular}{|c|c|c|}
\hline Statements & $\mathbf{M}$ & SD \\
\hline $\begin{array}{l}\text { I believe the human service professions, especially counselling has done well to meet the cultural } \\
\text { need of clients in Ghana. }\end{array}$ & 2.40 & 0.72 \\
\hline $\begin{array}{l}\text { I consider the value expectations innate in the main school of thoughts of counselling and } \\
\text { comprehend the way these expectations might encounter with the beliefs of Ghanaian culture of } \\
\text { the help seekers. }\end{array}$ & 2.31 & 0.65 \\
\hline $\begin{array}{l}\text { I am mindful of both the initial barriers and benefits culture brings to bear during counselling } \\
\text { sessions. }\end{array}$ & 2.98 & 0.50 \\
\hline I am well-informed of the ‘acculturation' simulations for different tribal groups in Ghana. & 2.15 & 0.57 \\
\hline $\begin{array}{l}\text { I am mindful of specific tribal beliefs that are ethnically native simulations of counselling for } \\
\text { diverse tribal groups in Ghana. }\end{array}$ & 1.82 & 0.63 \\
\hline I design culturally relevant interventions for clients & 1.67 & 0.66 \\
\hline I design programmes which facilitate contact to intervention by different help-seekers. & 1.84 & 0.74 \\
\hline Most of my clients attribute psychological problems to another person or spiritual being. & 3.16 & 0.56 \\
\hline During counselling sessions, ambiguity and stress often result from Ghanaian cultural beliefs. & 2.16 & 0.73 \\
\hline Total & 2.28 & 0.64 \\
\hline
\end{tabular}

Source: Field survey.

Table 1 shows the means by which the participants sampled perceived their multicultural knowledge competency. The table shows that statement 8 recorded the highest mean (3.16) with a standard deviation of 0.56. It is also shown that the participants agreed that they are 'mindful of both the initial barriers and benefits of culture brings to bear during counselling sessions' $(\mathrm{M}=2.98, \mathrm{~S} . \mathrm{D}=0.50)$.

On the contrary, the statement 'I design culturally relevant interventions for clients' recorded the least mean score (1.67) with a standard deviation of 0.66. Next to this, 'I am mindful of specific tribal beliefs that are ethnically native simulations of counselling for diverse tribal groups in Ghana' followed with a mean and standard deviation of 1.82 and 0.63 respectively. It is also shown that the statement 'I design programmes which facilitate contact to intervention by different help-seekers' $(\mathrm{M}=1.84, \mathrm{~S} . \mathrm{D}=0.74)$. The overall mean and standard deviation recorded in this section were $\mathrm{M}=2.28$ and $\mathrm{S} . \mathrm{D}=0.31$ which fell below the standard benchmark of 2.5. The responses on the knowledge section showed that the majority of the counsellors lack specific Ghanaian cultural knowledge of the groups they work with. The response pattern of this section was quite surprising considering generally traditional theories of counselling's assertion of being culturally relevant.

\subsection{Skills Section}

The Skills section was used to determine the extent to which counsellors view their basic counselling skills with regards to Ghanaian culture within the ethnic groups in Ghana and their ability to intervene in a manner that is culturally sensitive and relevant. The results are shown in Table 2.

\begin{tabular}{|c|c|c|}
\hline Statements & $\mathbf{M}$ & SD \\
\hline $\begin{array}{l}\text { I review my cultural counselling skills by monitoring my functioning via consultation, } \\
\text { supervision, and continuing education. }\end{array}$ & 2.31 & 0.83 \\
\hline $\begin{array}{l}\text { I apply specific counselling skills to create a successful outcome regardless of the client's } \\
\text { cultural background. }\end{array}$ & 2.64 & 0.57 \\
\hline $\begin{array}{l}\text { I am aware of certain counselling skills, techniques or approaches that are more likely to } \\
\text { transcend culture and be effective with any clients. }\end{array}$ & 2.64 & 0.53 \\
\hline $\begin{array}{l}\text { I am aware of the differential interpretations of nonverbal communication (e.g., personal } \\
\text { space, eye contact, handshakes) within various ethnic groups in Ghana. }\end{array}$ & 2.29 & 0.63 \\
\hline $\begin{array}{l}\text { I realise that counsellor-client incongruities in problem conceptualisation maybe as a result of } \\
\text { my inability to view the client's problem from his cultural perspective. }\end{array}$ & 2.51 & 0.70 \\
\hline $\begin{array}{l}\text { I have a large repertoire of verbal and nonverbal skills to match with the cultural contexts of } \\
\text { different clients. }\end{array}$ & 2.20 & 0.76 \\
\hline $\begin{array}{l}\text { I am skilled in a variety of different helping roles, methods, or approaches of the various } \\
\text { ethnic groups in Ghana. }\end{array}$ & 1.69 & 0.63 \\
\hline I am competent to communicate when a help-seeker's issue emanates from ethnic bias. & 2.36 & 0.68 \\
\hline Total & 2.31 & 0.67 \\
\hline
\end{tabular}

Table 2 shows the views of the participants concerning skills competence. The statement 'I am aware of certain counselling skills, techniques or approaches that are more likely to transcend culture and be effective with any clients' recorded a mean score of 2.64 and a standard deviation of 0.53. Similarly, the statement 'I apply specific counselling skills to create a successful outcome regardless of the client's cultural background' also recorded a mean of 2.64 and a standard deviation of 0.57 . Furthermore, the statement 'I realise that counsellor-client 
incongruities in problem conceptualization maybe as a result of my inability to view the client's problem from his cultural perspective' obtained a mean of 2.51 and standard deviation of 0.70 .

On the other hand, 'I am skilled in a variety of different helping roles, methods, or approaches of the various ethnic groups in Ghana' recorded the lowest mean $(\mathrm{M}=1.69, \mathrm{~S} . \mathrm{D}=0.63)$; I have a large repertoire of verbal and nonverbal skills to match with the cultural contexts of different clients $(M=2.20$ and S.D $=0.4)$ and I am able to tell when a client's problem relates to cultural bias $(\mathrm{M}=2.36$ and $\mathrm{S} . \mathrm{D}=0.68)$. This implies that less is done by participants to acquire the requite skills necessary for helping clients from diverse backgrounds with regards to indigenous models of helping. The overall mean score and standard deviation on this section were as follows; $\mathrm{M}=2.31$ and $\mathrm{S} . \mathrm{D}=0.33$. This indicates that counsellors from the selected public universities perceived their skills competency to be low. From the item means and distribution of responses on the Skills Section, it gives an indication that counsellors need multicultural training to be equipped with multicultural counselling skills based on cultural models and beliefs of the various ethnic groups in Ghana. This may help them to be effective when they encounter any difficulty during the counselling session.

\subsection{Awareness Section}

The third section, Awareness (Attitude-Belief), measured the extent to which counsellors are sensitive to their personal values and biases and how these may influence perceptions of their client, client's problem and the counselling relationship. Table 3 presents the means and standard deviations of the items on the awareness (attitude-beliefs) section.

Table-3. Awareness competency.

\begin{tabular}{|c|c|c|}
\hline Statements & $\bar{M}$ & SD \\
\hline $\begin{array}{l}\text { I am comfortable with differences that exist between me and my clients in terms of cultural values } \\
\text { and beliefs. }\end{array}$ & 3.29 & 0.51 \\
\hline $\begin{array}{l}\text { I think clients who do not discuss intimate aspects of their cultural lives are not being resistant and } \\
\text { defensive. }\end{array}$ & 1.69 & 0.68 \\
\hline I recognise cultural beliefs affect psychosocial functioning and expressions of the distress of clients & 2.27 & 0.75 \\
\hline $\begin{array}{l}\text { I recognise that beliefs and concepts of emotional well-being vary significantly from ethnic group to } \\
\text { ethnic group during the counselling session. }\end{array}$ & 2.42 & 0.54 \\
\hline I recognise that the client's problems are culturally based during the counselling session. & 2.09 & 0.67 \\
\hline $\begin{array}{l}\text { I accept that responses to client's conditions and related treatment/interventions are heavily } \\
\text { influenced by culture during counselling sessions. }\end{array}$ & 2.47 & 0.82 \\
\hline I become sad and apologetic when giving bad news to clients. & 3.11 & 0.49 \\
\hline I convey messages through proverbs, wise sayings and analogies to clients. & 2.60 & 0.77 \\
\hline $\begin{array}{l}\text { I agree that problems or illness come from chance occurrences: from both social and spiritual } \\
\text { imbalances. }\end{array}$ & 2.76 & 0.61 \\
\hline I am able to describe the social problems of the ethnic groups in my service area. & 2.31 & 0.56 \\
\hline $\begin{array}{l}\text { To a large extent, I know the demographics, beliefs and values within communities of my service } \\
\text { area. }\end{array}$ & 2.27 & 0.54 \\
\hline $\begin{array}{l}\text { I understand the social service needs within the ethnic groups that go unaddressed by the formal } \\
\text { counselling service system in my community of service. }\end{array}$ & 2.24 & 0.48 \\
\hline $\begin{array}{l}\text { I am able to enshrine Ghanaian cultural values and beliefs during the counselling process to impart } \\
\text { the society's concepts of desirable morals. }\end{array}$ & 2.02 & 0.71 \\
\hline Total & 2.46 & 0.63 \\
\hline
\end{tabular}

Source: Field survey.

Table 3 shows awareness as indicated by participants. The statement 'I am comfortable with differences that exist between me and my clients in terms of cultural values and beliefs' recorded the highest mean (3.29). Next to this, 'I become sad and apologetic when giving bad news to clients' $(\mathrm{M}=3.11, \mathrm{SD}=0.49)$; 'I agree that problems or illness come from chance occurrences: from both social and spiritual imbalances' $(\mathrm{M}=2.76, \mathrm{SD}=0.61)$ and 'I convey messages through proverbs, wise sayings and analogies to clients' $(\mathrm{M}=2.60, \mathrm{SD}=0.77)$. With the exception of these four items, in which their mean scores were above the standard benchmark of 2.5 indicating a high awareness competency. The remaining nine items in the Awareness (Attitude-Belief) section recorded mean scores below the standard benchmark for all counsellors which indicated a low multicultural awareness on those items.

Particularly, the statements 'I think that clients who do not discuss intimate aspects of their cultural lives are not being resistant and defensive' $(\mathrm{M}=1.69, \mathrm{SD}=0.68)$; 'I am able to enshrine Ghanaian cultural values and beliefs during the counselling process to impart the society's concepts of desirable morals' $(\mathrm{M}=2.02, \mathrm{SD}=0.71)$; 'I recognise that client's problems are culturally based during the counselling session' $(\mathrm{M}=2.09$, SD=0.67); 'I understand the social service needs within the ethnic groups that go unaddressed by the formal counselling service system in my community of service' $(\mathrm{M}=2.24, \mathrm{SD}=0.48)$. The overall mean and standard deviation scores obtained in this section were as follows; $\mathrm{M}=2.46$ and $\mathrm{S} . \mathrm{D}=0.22$. The overall mean score of 'Awareness' obtained fell below the standard benchmark of 2.5 indicating low 'Awareness' competency.

The analysis of the data gathered from this research categorised participants into two groups identifying counsellors at either a low (where means of section <2.5) or high (where means of section $\geq 2.5$ ) level of multicultural competence. Through an examination of the variables associated with these two groups, it can be concluded that counsellors labelled as low multicultural competent have not taken courses in multicultural training and workshop. The overall mean scores indicate that counsellors perceive their level of multicultural awareness competence in a counselling session to be low irrespective of the gender of counsellors. Table 4 presents the means and standard deviations of CC sections based on gender. 


\begin{tabular}{|c|c|c|c|c|c|c|c|c|c|}
\hline \multirow[t]{2}{*}{ Sections } & \multicolumn{3}{|c|}{ Male } & \multicolumn{3}{|c|}{ Female } & \multicolumn{3}{|c|}{ Total } \\
\hline & $\mathbf{M}$ & SD & $\mathbf{N}$ & $\mathbf{M}$ & SD & $\mathbf{N}$ & $\mathbf{M}$ & SD & $\mathbf{N}$ \\
\hline Awareness & 2.45 & 0.76 & 25 & 2.41 & 0.50 & 20 & 2.43 & 0.63 & 45 \\
\hline Knowledge & 2.32 & 0.73 & 25 & 2.24 & 0.55 & 20 & 2.28 & 0.64 & 45 \\
\hline Skills & 2.35 & 0.86 & 25 & 2.27 & 0.48 & 20 & 2.31 & 0.67 & 45 \\
\hline Total & 2.37 & 0.78 & 25 & 2.31 & 0.51 & 20 & 2.34 & 0.65 & 45 \\
\hline
\end{tabular}

Source: Field survey.

Table 4 shows that the mean of means score of multicultural competence of counsellors is 2.23. This figure is lower than 2.50 indicating low multicultural competence of counsellors in Ghanaian public universities. From Table 4, participants who participated in the study perceived their multicultural counselling competency to be low in terms of the three sections they were measured on namely; Knowledge, Skills and Awareness (Beliefs-Attitude). These results indicate that counsellors based upon gender, perceived all sections to be low in their multicultural counselling competence, they were unanimous in perceiving multicultural competency to be low. These findings may be an indication that multicultural counselling is not given attention in Ghana. Ghana's culture is multi-ethnic and diverse in nature with people from different background.

\section{Discussion}

The study revealed that counsellors sampled perceived their cultural competency to be low as measured on all sections (Knowledge, Skills and Awareness). This low cultural competence is portrayed by looking at the overall means on the sections as well as the overall mean (2.34) of the MCQ whose mean scores obtained were lower than the standard benchmark (2.50). This tally with the demographic data obtained from participants, which indicates that only a few of them have received or participated in multicultural training. The study revealed that the majority of the counsellors lack specific Ghanaian cultural knowledge of the groups they work with. The findings of the present study corroborate with the findings of Sodowsky et al. (1998) that having information and being knowledgeable of cultural characteristics that exist among ethnic groups adds to the active utilisation of ethnically applicable and persuasive approaches. This is because counsellors have a piece of decent information and the understanding of their perceived worldview, but have inadequate information about the cultures of other people they work with.

The study revealed that counsellors lack multicultural skills with regards to the cultural beliefs of the different ethnic groups in Ghana which makes them incapable to mediate in a way that is ethnically subtle and applicable. The findings are consistent with the finding obtained by Gyekye (2013) that helping professionals have inadequate skills to develop intervention and strategies needed in working with multi-ethnic groups in Ghana. The findings of the current study further tally with the findings of Sue and Sue (2016) that a counsellor's inability to mediate in a way that is socio-culturally subtle and appropriate hinders the progress of counselling services.

The study showed that counsellors have a low awareness level with regards to her/his subjective beliefs and prejudices and the way such things might impact opinions of the help-seeker, the help-seeker's issue and the therapeutic process. The findings of the current study give the impression that counsellors hardly find out the consciousness (awareness) of their personal conventions, beliefs and prejudices, in addition to being thoughtful of a different help-seeker's worldview. The findings of the study validate the findings of Sue (2008) that if help-seeking professionals are conscious of the effects of culture on their personal disposition and social lifestyles, then counsellors could well be able to recognise the approaches which cultural values and traditions impact the behaviours of the client, relations, beliefs and lifetime aims. Competency originates with consciousness (awareness) of an individual's specific cultural beliefs and values in relation to other people's culture. Furthermore, being aware of the socio-culturally knowledgeable traditions controls a life, by means of or devoid of a person's approval.

This situation needs attention, therefore, counsellors in Ghana should be knowledgeable and be able to understand various indigenous methods, values and beliefs about healing within the various ethnic groups as a result of cultural values that can be said to be shared by the different ethnocultural and tribal groups in Ghana. The current study highlight the prerequisite to recognise the essence of our belief systems and values of helping people in need which have been marginalised by the traditional theories. It appears cultural workshops to train counselling professionals at the Ghanaian public universities are limited as well as multicultural, diversity and inclusion centres.

\section{Conclusions}

This study called for an assessment of the multicultural competences of counselling professionals. The findings of the study have shown that counsellors' multicultural competencies were low for all sections; Awareness (Attitude-Beliefs), Skills and Knowledge. Multiculturalism has been seen as a vehicle for professional development which can eventually lead to counselling transformation in Ghana. By integrating multicultural theoretical framework (awareness, skills and knowledge) into the training of counsellors in Ghana, the diverse ethnic, tribal and cultural nature of our country would benefit more from counselling; a subject area brought nearby to the people.

\section{Implications for Practice}

From the findings and conclusion, the counsellors need to pay attention to Ghanaian culture in relation to the specific ethnic and tribal groups. These will inform them of the basic elements identified in the cultures of these small groups in Ghana. To make counsellors effective, multicultural training, diversity and inclusion centres must be established by management and the leadership of the universities in Ghana to facilitate effective counselling service. Furthermore, psychology and counselling programmes need to be diffused multiculturalism recognising pertinent issues with regard to death, marriage rites, age, sex, values, beliefs, religion, widowhood, taboos, etc., of the various ethnic tribes in Ghana. 


\section{Recommendations}

1. Counsellors should attend multicultural awareness training and workshop about Ghanaian cultural beliefs and ethnic diversity.

2. The management of public universities in Ghana should establish Multicultural Training Centres to promote diversity and inclusion in the services provided.

3. Multiculturalism content should be diffused entirely into the current coursework in counselling and psychology programmes in the counsellor trainee universities in Ghana.

\section{References}

Arthur, N. and K. Achenbach, 2002. Developing multicultural counseling competencies through experiential learning. Counselor Education and Supervision, 42(1): 2-14.Available at: https://doi.org/10.1002/j.1556-6978.2002.tbo1299.x.

Dorazio, C., 2013. The impact of ethnic identity on attitude towards counselling for Italian-Americans. A PhD Thesis Submitted to Columbia University, New York City. Available from https://academiccommons.columbia.edu/doi/10.7916/D8086CN4.

Fraenkel, J.R. and N.E. Wallen, 2000. How to design and evaluate research in education. 4th Edn., Pennsylvania PA: McGraw-Hill Company Inc.

Gyekye, K., 2013. Philosophy, culture and vision: African perspective. Accra Ghana: Sub-Saharan Publishers.

Hays, D.G., 2008. Assessing multicultural competence in counselor trainees: A review of instrumentation and future directions. Journal of Counseling \& Development, 86(1): 95-101.

Ivey, A.E., 1994. Intentional interviewing and counselling. Monterey: Brooks/Cole Publishing Company.

Lee, C.C., 2013. Multicultural issues in counselling: New approaches to diversity. 4th Edn., Alexandria: American Counselling Association.

Molenberghs, G., 2013. Survey methods and sampling techniques. Katholieke Universiteit Leuven and Universiteit Hasselt, Interuniversity Institute for Biostatistics and Statistical Bioinformatics, Belgium. [PRESENTATION].

Ridley, C.R. and A.J. Kleiner, 2003. Multicultural counselling competence: History, themes, and issues, in D. B. Pope-Davis, H. L. K. Coleman, W. L. Ming, R. L. Toporek (Eds) Handbook of multicultural competencies in counselling and Psychology, Thousand Oaks: Sage Publication. pp: 3-20.

Sodowsky, G.R., P.Y. Kuo-Jackson, M.F. Richardson and A.T. Corey, 1998. Correlates of self-reported multicultural competencies: Counselor multicultural social desirability, race, social inadequacy, locus of control racial ideology, and multicultural training. Journal of Counseling Psychology, 45(3): 256-264.Available at: https://doi.org/10.1037//0022-0 167.45.3.256.

Sue, D.W., 2001. Multidimensional facets of cultural competence. The Counseling Psychologist, 29(6): 790-821.Available at: https://doi.org/10.1177/0011000001296002.

Sue, D.W., 2008. Multicultural organizational consultation: A social justice perspective. Consulting Psychology Journal: Practice and Research, 60(2): 157-169.Available at: https://doi.org/10.1037/0736-9735.60.2.157.

Sue, D.W., J.E. Bernier, A. Durran, L. Feinberg, P. Pedersen, E.J. Smith and E. Vasquez-Nuttall, 1982. Position paper: Cross-cultural counseling competencies. The Counseling Psychologist, 10(2): 45-52.Available at: https://doi.org/10.1177/0011000082102008.

Sue, D.W. and D. Sue, 2003. Counseling the culturally diverse: Theory and practice. 4th Edn., New York NY: John Wiley \& Sons.

Sue, D.W. and D. Sue, 2016. Counseling the culturally diverse: Theory and practice. 7 th Edn., Hoboken: John Wiley \& Sons.

Sue, S., N. Zane, G.C. Nagayama Hall and L.K. Berger, 2009. The case for cultural competency in psychotherapeutic interventions. Annual Review of Psychology, 60: 525-548.Available at: https://doi.org/10.1 146/annurev.psych.60.1 10707.163651.

Talib, M.A., 2010. Cultural influences and mandated counseling in Malaysia. Asian culture and History, 2(1): 28-33.Available at: https://doi.org/10.5539/ach.v2n1p28. 